\title{
FLOW-INJECTION SPECTROMETRIC DETERMINATION OF SODIUM DICLOFENAC IN PHARMACEUTICAL FORMULATIONS
}

\author{
E. F. SILVA', P. R. B. GOMES, R. N. FERNANDES $S^{l}$, W. S. LYRA ${ }^{2 *}$ \\ ${ }^{1}$ Departamento de Química, Universidade Federal do Maranhão, Zip Code 65080-540, São Luís-MA, Brazil \\ ${ }^{2}$ Departamento de Química, Universidade Federal da Paraíba, Zip Code 58051-970, João Pessoa-PB, Brazil
}

\begin{abstract}
A flow-injection spectrometric method for determination of sodium diclofenac in pharmaceutical formulations was developed on this work. Sodium diclofenac solutions were injected into a stream of deionized water that reacted with potassium permanganate on acid medium producing Mn ${ }^{2+}$ ions whose exhibit maximum absorbance at $450 \mathrm{~nm}$. The methodology used optimize experimental parameters was $3^{3}$ factorial design and response surface. The proposed method obeyed the Beer's Law over the range 25-160 mg L-1, applied in tablets and ampoules samples. Results were compare with the reference method. It was verified at the $95 \%$ confidence level, through paired $t$-test application - there is no statistic difference between them. The detection limit was valued in 2.6 mg $\mathrm{L}^{-1}$, relative standard deviation for 10 consecutive injections was $1.5 \%\left(100.0 \mathrm{mg} \mathrm{L}^{-1}\right.$ sodium diclofenac solution) and the sample throughput was $80 \mathrm{samples}^{-1}$. Regarding optimization of operational conditions, the FIA spectrometric method presented analytical performance as good as other elaborated flow analyzers. Offers a simple and inexpensive way to this drug indirect determination aiming quality control on pharmaceutical industry's assembly line. However, it can not be used for adulteration screening analysis due to non-selectivity and non-specificity of redox reactions.
\end{abstract}

Keywords: Sodium diclofenac, flow-injection analysis, injectable solutions, tablets.

\section{INTRODUCTION}

The use of sodium diclofenac, sodium salt of 2-[(2,6-dichlorophenyl) amino] benzene acetic acid, for treatment of inflammations was reported since $1975 .{ }^{1}$ It is a relatively safe and effective non-steroidal anti-inflammatory drug (NSAID) with pronounced anti-rheumatic, anti-inflammatory, analgesic and antipyretic properties. ${ }^{2}$ In Brazil, for several treatments, sodium diclofenac is prepared in a wide range of formulations including tablets, ampoules, capsules, gels, lotions, suppositories and ointments. Sodium diclofenac acts directly in the liver over the metabolic pathway of the "arachidonic acid cascade" inhibiting the cyclooxygenases (COX) enzymes and consequently the biosynthesis of prostaglandins in inflammatory processes. ${ }^{3}$

Thus sodium diclofenac importance for pharmaceutical industry and its widespread use, have been efforts to develop reliable methods for its determination. ${ }^{4}$ Several batch methods are in literature to sodium diclofenac determination: potentiometric titration, ${ }^{5}$ Ultra Violet (UV) spectrometry, ${ }^{6,7}$ Liquid Chromatography (LC), ${ }^{8}$ High Performance Liquid Chromatography (HPLC), ${ }^{9,10}$ Digital Image-Based Flame Emission Spectrometry (DIB-FES), ${ }^{11}$ Flame Atomic Absorption Spectrometry (FAAS), ${ }^{3}$ Capillary Electrophoresis (CE), ${ }^{12,13}$ Liquid Chromatography Atmospheric-Pressure Chemical Ionization Mass Spectrometry (LC-APCI-MS), ${ }^{14}$ Differential Scanning Calorimetry (DSC), ${ }^{15}$ Nuclear Magnetic Resonance (NMR), ${ }^{16}$ Fluorescence, ${ }^{17}$ Near Infrared (NIR) spectrometry ${ }^{18}$ and voltammetry. ${ }^{19,20}$ The majority of previously mentioned methods are expensive with high maintenance cost making them less attractive to routine analysis.

Regarding simplicity, cost of instrumentation and maintenance, Visible (VIS) Spectrometry arises as an interesting and accessible alternative for routine analysis in industry and teaching due to its reasonable sensitivity, ${ }^{4}$ selectivity and specificity. Same as other techniques, several visible spectrometric batch methods for sodium diclofenac determination have been reported., ${ }^{421-37}$ However, several of these methods consist on elaborated procedures with manipulation steps.

Nowadays, there is a big challenge to pharmaceutical industry, the development of faster, lesser expensive and more accurate ${ }^{38}$ new analytical methodologies in order to guarantee drug content, identify adulterants in medicines which represent health risks ${ }^{39}$ and reduce (or replace) materials harmful to human health and environment. ${ }^{40}$ For these purposes, flow systems are excellent tools to deal with solutions in wet chemical analysis ${ }^{41}$ since automation is a key demand on analytical chemistry. ${ }^{42}$ Flow Injection Analysis (FIA) has first been introduced by Ruzicka and Jansen in $1975^{43}$ and can be defined as a simple and versatile analytical methodology for automating wet chemical analysis, based on physical and chemical manipulation of a dispersed sample zone formed by the injection of the sample into flowing carrier stream and detection downstream. ${ }^{44}$ These technique became very popular in laboratories on past five decades and currently is replacing solutions' manual handling because is computer compatible and allows automated handling of samples and reagent solutions with strict reaction conditions control. ${ }^{42}$

Although several reports of visible spectrometric of sodium diclofenac determination batch methods on literature, few FIA visible spectrometric methods have been published..$^{45-47}$ Moreover they use unusual reagents ${ }^{45,47}$ and were not optimized in order to provide maximum sensitivity and reach lower: consumption of samples and reagents and waste generation, Limit of Detection (LOD) and Limit of quantification (LOQ).

This paper proposes a flow-injection system for visible spectrometric determination of sodium diclofenac in tablets and ampoules by using its reaction with potassium permanganate in acid medium under optimized experimental conditions.

\section{MATERIAL AND METHODS}

\section{Reagents, solutions, and samples}

All chemicals were from analytical grade and all solutions were prepared with water from a Millipore (Bedford, MA) Milli-Q (Model UV Plus Ultra-Low Organics water). A $1000 \mathrm{mg} \mathrm{L}^{-1}$ stock solution of sodium diclofenac (Sigma, St. Louis, MO, USA) was prepared dissolving a suitable amount of the salt in deionized water. The calibration solutions with ten levels of concentration of sodium diclofenac $\left(20.0-160.0 \mathrm{mg} \mathrm{L}^{-1}\right)$ were prepared by suitable dilution from their respective stock solutions in deionized water. An approximately 1.2 x $10^{-1} \mathrm{mmol} \mathrm{L}^{-1} \mathrm{KMnO}_{4}$ (Merck, Darmstadt, Germany) solution was prepared by dissolving a suitable amount of the salt in approximately $100.0 \mathrm{mmol} \mathrm{L}^{-1}$ $\mathrm{H}_{2} \mathrm{SO}_{4}$ (Merck, Darmstadt, Germany) aqueous solution. Five brands of sodium diclofenac ampoules and tablets, with a nominal content of $25 \mathrm{mg} \mathrm{mL}^{-1}$ and 500 $\mathrm{mg}$ respectively, were purchased from local drugstores.

For ampoules, before analysis, were diluted with deionized water in order to interpolate the analytical signals in the method linear range response.

For tablets, twenty tablets were grinded in a mortar to yield a fine powder and the average mass of them were dissolved in deionized water. Afterwards, a filtration to remove the insoluble particles was performed with ashless filter paper (Whatman $\mathrm{n}^{\circ} 40$ ). The resulting solution was diluted to a final volume $(100 \mathrm{~mL})$ with deionized water. Then, this solution was diluted in deionized water to read analytical signals in the method linear response.

\section{Apparatus}

A schematic diagram of the acrylic flow manifold can be seen on Fig. 1. An eight-channel Ismatec (Zurich, Switzerland) Model IPC-8 peristaltic pump supplied with polyethylene pump tubes $(0.8 \mathrm{~mm}$ i.d.) was used for fluids propulsion. Standard/sample solutions were injected into the carrier stream using a proportional injector. ${ }^{48,49}$ Spectrophotometric measurements for the proposed method were performed with a Femto (São Paulo, Brazil) Model 700 Plus spectrophotometer equipped with a quartz flow cell (optical 
path $1.0 \mathrm{~cm}$ ). A Three-way homemade confluence connector of acrylic was used as well. System management was carried out by means of a Pentium II microcomputer equipped with A PCL711S (Advantch Corp., Ohio, USA) interface. Data acquisition and processing were carried out with a software written in QuickBasic Version 4.5.
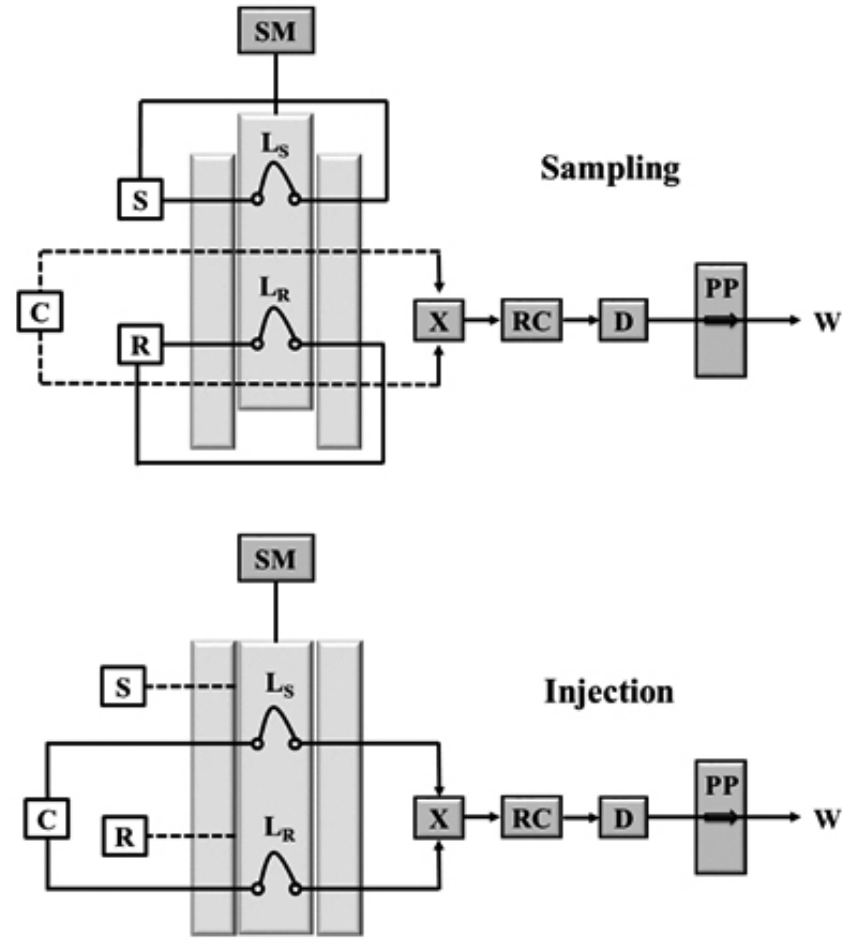

Figure 1. Diagram of the proposed FIA system: $\mathrm{C}=$ carrier, $\mathrm{S}=$ sample, $\mathrm{R}$ $=$ reagent, $\mathrm{L}_{\mathrm{S}}=$ sample loop, $\mathrm{L}_{\mathrm{R}}=$ reagent loop, $\mathrm{SM}=$ step motor, $\mathrm{RC}=$ reaction coil, $\mathrm{PP}=$ peristaltic pump, $\mathrm{X}=$ confluence point, $\mathrm{D}=$ spectrophotometer and $\mathrm{W}=$ waste. Narrows indicate the direction of the fluids

At the sampling position of the proportional injector (Fig. 1) reagent (R) and sample (s) keep recycling and filling their respective loops $\left(L_{R}\right.$ and $\left.L_{S}\right)$ The use of a loop for reagent aims to reduce reagent consumption. Changing the position of the proportional injector releases the injection of the sample and reagent aliquots in the carrier stream (deionized water). Both are aspirated by the peristaltic pump (PP) towards the confluence point (X) and then are mixed in the reaction coil (RC) to assure a complete homogenization before reaching the detector (D). After reaction and measurement, the solutions were collected in the waste disposal device (W).

\section{FIA procedure}

At a flow-rate of $1.0 \mathrm{~mL} \mathrm{~min}^{-1}$ sample and reagent solution are continuously pumped through the system. A sample aliquot of $50.0 \mu \mathrm{L}$ and a reagent aliquot of $35.0 \mu \mathrm{L}$ are injected in the carrier stream. The transient signal (absorbance at $431 \mathrm{~nm}$ ) increase obeys the Beer's Law. Therefore, the calibration curve can be used to perform analysis of sodium diclofenac in pharmaceutical formulations. It is possible carry out injections every 45 seconds. Since the pumping flowrate can be accelerate to its maximum value, after signal acquisition, tota analysis time can be reduced.

\section{Reference method}

A direct UV spectrometric method is described in Brazilian pharmacopoeia for the determination of sodium diclofenac. ${ }^{6}$ These measurements were carried out at $258 \mathrm{~nm}$ in methanol medium (solvent/blank)

\section{RESULTS AND DISCUSSION}

\section{Choice of the analytical response}

In aqueous solution, potassium permanganate reacts with sodium diclofenac on acid medium to produce $\mathrm{Mn}^{2+}$ ions, which exhibits maximum absorbance at $431 \mathrm{~nm}$. The absorbance is proportional to the concentration of sodium diclofenac in the sample. The reaction is displayed on Fig. 2.

According to Fig. 2 the reaction between sodium diclofenac and permanganate on acid medium provide two ways of being monitored wavelength of maximum absorbance of the reagents or the products. Both sodium diclofenac and its oxidation product absorb radiation in the UV region, while permanganate and $\mathrm{Mn}^{2+}$ ions have distinct absorption of radiation on the visible region. The visible region was choose for measurements because its selectivity. ${ }^{50}$

As demonstrated in Fig. 3 (a) the absorption spectrum of permanganate (tetrahedral $\mathrm{d}^{0}$ ion) appeared as six maxima peaks (at 468, 490, 508, 526, 546 and $566 \mathrm{~nm}$, respectively) which could be attributed to vibronic features; due to Jahn-Teller active normal modes that leads to minima distorted (lowersymmetry) geometries. ${ }^{51-53}$ As also shown in Fig. 3 (b) the absorption spectrum of $\mathrm{Mn}^{2+}$ ions (octahedral $\mathrm{d}^{5}$ ion) appeared as two maxima peaks which is attributed to transitions ${ }^{6} \mathrm{~A}_{1 \mathrm{~g}} \leftarrow{ }^{4} \mathrm{~T}_{2 \mathrm{~g}}(\mathrm{G})$ (at $431 \mathrm{~nm}$ ) and ${ }^{6} \mathrm{~A}_{1 \mathrm{~g}} \leftarrow{ }^{4} \mathrm{~T}_{1 \mathrm{~g}}$ (G) (at $538 \mathrm{~nm}){ }^{54}$

In a visual inspection of Fig. 3 (a) and (b), can be observed that the absorption of the permanganate ion at $431 \mathrm{~nm}$ is negligible and so is the absorption of the $\mathrm{Mn}^{2+}$ ion at $526 \mathrm{~nm}$. Therefore, there is no evidence of choice limitation of both wavelengths for measurements. The only difference is in the profile of the analytical curve, as described below.

Monitoring permanganate: as the concentration of sodium diclofenac increases, more permanganate will be consumed and consequently it absorbance (at $526 \mathrm{~nm}$ ) will decrease. As result, the analytical curve will be downward.

Monitoring $\mathrm{Mn}^{2+}$ : as the concentration of sodium diclofenac increases, more permanganate is consumed producing more $\mathrm{Mn}^{2+}$ ions. As result, the absorbance of $\mathrm{Mn}^{2+}$ ion (at $431 \mathrm{~nm}$ ) will increase and the analytical curve will be upward.

Comparing the values of molar attenuation coefficient $(\varepsilon)$ of permanganate and $\mathrm{Mn}^{2+}$ ions at their respective absolute maxima wavelengths, it would be reasonable to choose absorbance measurements at $526 \mathrm{~nm}$ as analytical response, since there is good sensitivity in analytical method $\varepsilon$ values should be at least in the order of $10^{3} .{ }^{44}$

The extent of the analytical method linear range depends of sensitivity of the analytical response used in the construction of the analytical curve. Most sensitive analytical curves leads to narrower linear ranges while less sensitive analytical curves leads to wider linear ranges. Since the method developed in this work aimed the production line on the pharmaceutical industry, the need for a sensitive method is nor critical. For this specific case is more import to develop a method with a wide linear range which allows to analyze samples with quite different contents of sodium diclofenac. Therefore, the wavelength of maximum absorbance of the $\mathrm{Mn}^{2+}$ ion $(431 \mathrm{~nm})$ was selected as analytical response to construct analytical curves.

\section{Optimization of FIA system}

In the development of analytical methodologies, the optimization (maximization or minimization) of experimental conditions (variables) is a prior. Literature provides two approaches for this optimization: the univariate and multivariate.

The optimization using the univariate approach is often described in flowbased methodologies. It consists in the optimization of variables one-by-one varying levels of one variable while others are held at constant levels. ${ }^{50}$ Three disadvantages are associated with this approach: (1) It is time and reagentconsuming, (2) It is unable to identify and consider interaction effect between variables and (3) The maximum efficiency of the analytical methodology might not be obtained.

Unlike the univariate approach, the multivariate is not described often in flow-based methodologies. It consists in the optimization on the shortest way with the following advantages: (1) Reduce the consumption of samples and reagents, (2) Minimize efforts, (3) Save time, (4) Able to identify and consider interaction effect between variables, (5) Reduce the amount of data, (6) Ease data interpretation, (7) Allow to access the ruggedness. ${ }^{55-57}$

For optimization of proposed methodology was used the factorial design and examination of the response surface. This step aims maximize the analytical response and provide a wider linear range. Initially, there are five variables to be optimized: flow rate, reagent loop length $\left(\mathrm{L}_{\mathrm{R}}\right)$, sample loop length $\left(\mathrm{L}_{\mathrm{S}}\right)$, concentration of reagent and reaction coil length. Since the reagent concentration increases the number of moles of $\mathrm{Mn}^{2+}$ ions that reach the detector, it was fixed in $1.2 \times 10^{-1} \mathrm{mmol} \mathrm{L}^{-1} . \mathrm{L}_{\mathrm{S}}$ and $\mathrm{L}_{\mathrm{R}}$ are directly related with 
their respective volumes and consequently the number of moles of $\mathrm{Mn}^{2+}$ ions that reach the detector. In order to work with sample acting as limiting reagent, $\mathrm{L}_{\mathrm{S}}$ was fixed in $10.0 \mathrm{~cm}(50.0 \mu \mathrm{L})$.

The remaining variables then were code: reagent loop length, $L_{R},(A)$, reaction coil length $(B)$ and flow rate $(C)$. For each one, a minimum (-), a zero
(0) and a maximum (+) value was assigned as summarized in Table 1 . The effects evaluation of these variables over the analytical response was conducted by means of a $3^{3}$ factorial design. Every run was carried out in authentic duplicate, totalizing 54 experiments.

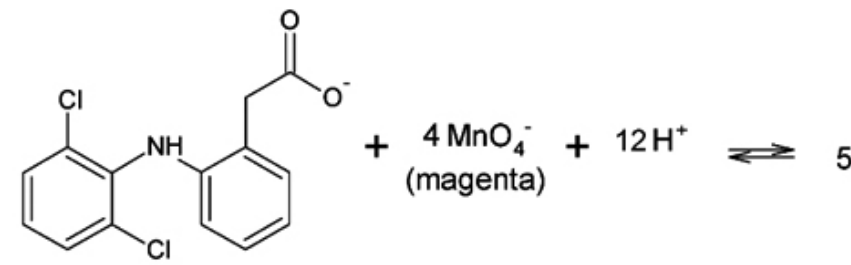

5

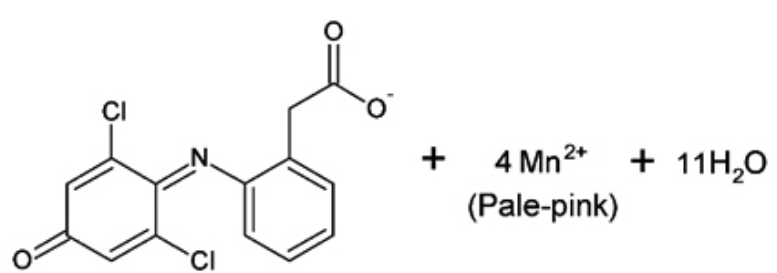

Figure 2. Reaction between sodium diclofenac and potassium permanganate on acid medium.
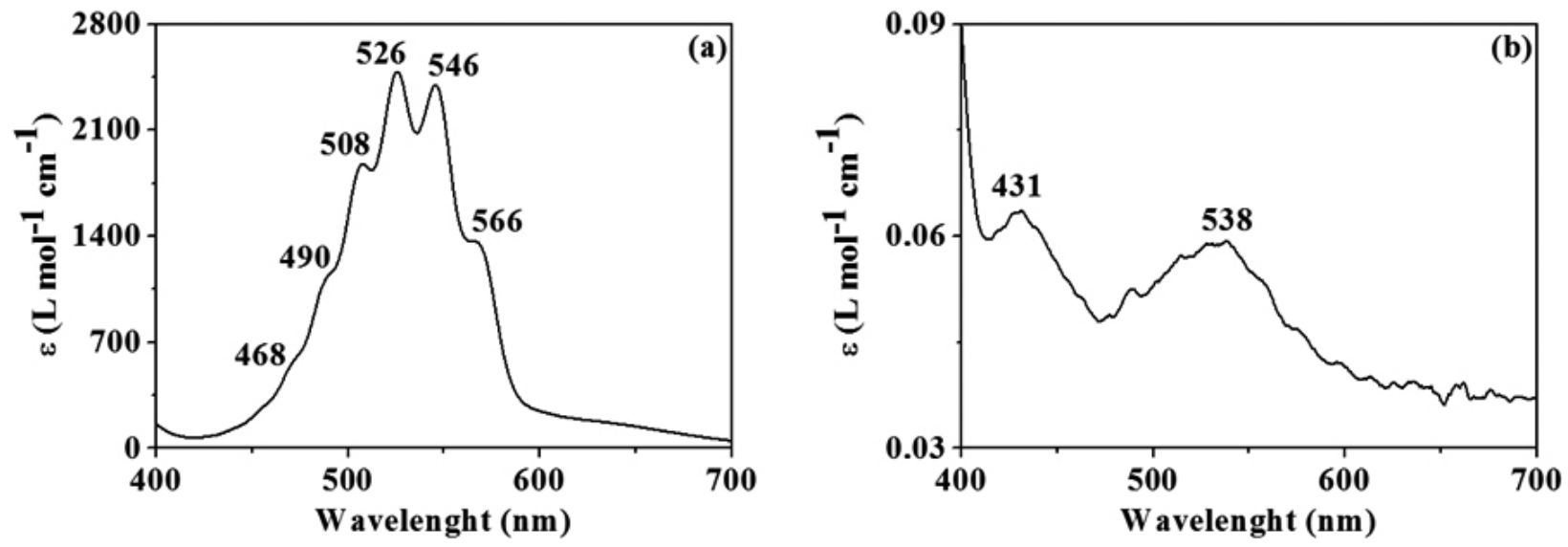

Figure 3. Absorption spectra in the visible region of: (a) permanganate $\left(\mathrm{MnO}_{4}^{-}\right)$and (b) $\mathrm{Mn}^{2+}$ ions, both in acid medium.

Table 1. Variables and levels used in the $3^{3}$ factorial design.

\begin{tabular}{|c|c|c|c|c|}
\hline \multirow{2}{*}{ Code } & \multicolumn{2}{|c|}{ Variables } & \multicolumn{3}{|c|}{ Levels } \\
\cline { 3 - 5 } & & -1 & $\mathbf{0}$ & +1 \\
\hline A & Reagent loop length, $\mathrm{L}_{\mathrm{R}}(\mathrm{cm})$ & 5.0 & 7.5 & 10.0 \\
\hline B & Reaction coil length $(\mathrm{cm})$ & 20 & 40 & 60 \\
\hline C & Flow rate $\left(\mathrm{mL} \mathrm{min}^{-1}\right)$ & 1.0 & 1.5 & 2.0 \\
\hline
\end{tabular}

The influence of each variable and their respective interactions on the analytical response were calculated through matrix approach described in literature. ${ }^{58}$ The effects confidence interval and their respective meanings are presented in Table 2. Effects considered significant are those that confidence intervals do not contains "zero", 58

As expected, reagent loop length $L_{R}$ (A) exerts a positive influence to the analytical because it is directly relate with reagent concentration and increases the number of moles of $\mathrm{Mn}^{2+}$ ions that reach the detector.

Coil length reaction's influence (B) on the analytical response is not significant because the reaction between sodium diclofenac and potassium permanganate in acid medium is almost instantaneous. Therefore, it is not necessary reactions coils too long. However, using a $40 \mathrm{~cm}$ reaction coil provides stability in terms of base line of the analytical response.
Table 2. Effects confidence interval in $3^{3}$ factorial design.

\begin{tabular}{|c|c|c|}
\hline Effect & Confidence interval & Meaning \\
\hline Average & $0.1439 \pm 0.0435$ & Significant \\
\hline \multicolumn{4}{|c|}{ Primary effects } \\
\hline A & $0.0273 \pm 0.0145$ & Significant \\
\hline B & $-0.0037 \pm 0.0145$ & Not significant \\
\hline C & $-0.0427 \pm 0.0145$ & Significant \\
\hline & Secondary effects & Not significant \\
\hline AB & $-0.0133 \pm 0.0145$ & Significant \\
\hline AC & $0.0357 \pm 0.0145$ & Not significant \\
\hline BC & $0.0140 \pm 0.0145$ & Not significant \\
\hline \multicolumn{4}{|c|}{ Tertiary effect } \\
\hline ABC & $-0.0123 \pm 0.0145$ &
\end{tabular}

Flow-rate (C) exerts a positive influence on analytical response since it allows a fast homogenization of potassium permanganate discrete volumes and sodium diclofenac solutions for an almost instantaneous reaction.

Since $(B)$ is not significant, its secondary and tertiary interactions $(A B$, $\mathrm{BC}$ and $\mathrm{ABC}$, respectively) with others variables are not too. The secondary interaction effect of $\mathrm{L}_{\mathrm{R}}$ and flow-rate (AC) is positive because the proportional injector (with individual loops for reagent and sample) configuration that allows fast homogenization with low dispersion.

Since (B) does not exert influence on the analytical response, (A) and (C) were optimized means of surface response methodology ${ }^{58}$ by using a $3^{2}$ factorial 
design which was generated from the original $3^{2}$ factorial design original data using a $40 \mathrm{~cm}$ reaction coil. Fig. 3 shows the optimum point.

After optimization, the configuration of the definitive FIA method is: concentration of reagent $=1.2 \times 10^{-1} \mathrm{mmol} \mathrm{L}^{-1}$, sample loop, $\mathrm{L}_{\mathrm{s}}=10.0 \mathrm{~cm}(50.0$ $\mu \mathrm{L}$ ), reaction coil length $=40.0 \mathrm{~cm}$, flow rate $=1.0 \mathrm{~mL} \mathrm{~min}^{-1}$ and reagent loop, $\mathrm{L}_{\mathrm{R}}=7.0 \mathrm{~cm}(35.0 \mu \mathrm{L})$.

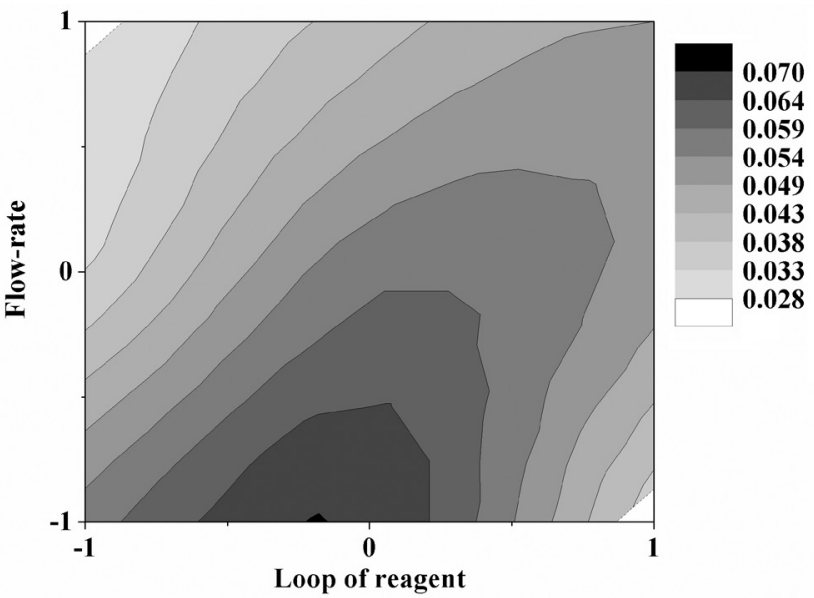

Figure 4. Response surface of the remaining $3^{2}$ factorial design. The optimal point (in black) corresponds to the following conditions: flow-rate $=-1$ $\left(1.0 \mathrm{~mL} \mathrm{~min}^{-1}\right)$ and loop of reagent $=-0.185(7.0 \mathrm{~cm})$.

\section{Analytical curve and figures of merit}

The permanganate method obtained a satisfactory analytical curve for sodium diclofenac determination in injectable solutions and tablets with the regression equation $R=(-0.04450 \pm 0.00548)+\left(0.00291 \pm 3.64 \times 10^{-5}\right)$ $C$; where $R$ is the analytical response and $\mathrm{C}$ is the analyte concentration in $\mathrm{mg} \mathrm{L}^{-1}$. The confidence intervals of the calibration model parameters () were estimated at the $95 \%$ confidence level. Since these confidence intervals contain the "zero", they are considered statistically insignificant.

For validation of the linear calibration model, have been implemented an analysis of variance (ANOVA) which consists to apply two $F$-tests: the first one for lack of fit and the second for significance of regression. ${ }^{59}$ The analytical curve was constructed based on three genuine repeated measurements in ten levels of sodium diclofenac concentration. The values of regression, residual, lack of fit and pure error were calculated using the mean squares (MS) presented in Table 3.

Table 3. Analysis of variance for the fit of a linear model $(\widehat{y}=\alpha+\beta X)$ of the analytical curve.

\begin{tabular}{|c|c|c|c|c|}
\hline Source & $\begin{array}{c}\text { Degrees of } \\
\text { freedom }\end{array}$ & $\begin{array}{c}\text { Mean square } \\
(\boldsymbol{M S})\end{array}$ & $\begin{array}{c}\boldsymbol{M S}_{\text {lack of fit }} \\
\boldsymbol{M S}_{\text {pure error }}\end{array}$ & $\begin{array}{c}\boldsymbol{M S}_{\text {regression }} \\
\boldsymbol{M S}_{\text {residual }}\end{array}$ \\
\hline Regression & 1 & $4.72 \times 10^{-1}$ & & \\
\hline Residual & 28 & $1.76 \times 10^{-5}$ & \multirow{2}{*}{$3.32 \times 10^{-2 \mathrm{a}}$} & \multirow{2}{*}{$2.68 \times 10^{4 \mathrm{~b}}$} \\
\hline Lack of fit & 8 & $8.08 \times 10^{-7}$ & & \\
\hline Pure error & 20 & $2.43 \times 10^{-5}$ & & \\
\hline
\end{tabular}

${ }^{\mathrm{a}} F_{\text {critical }}=2.45{ }^{\mathrm{b}} F_{\text {critical }}=4.20$. Both critical values are at the $95 \%$ confidence level.

Results of ANOVA are an indicative of a good fit in the analytical curve. In fact, the values of $\mathrm{MS}_{\text {lack of fit }} / \mathrm{MS}_{\text {pure error }}$ and $\mathrm{MS}_{\text {regression }} / \mathrm{MS}_{\text {residual }}$ are smaller and larger than the point of $F$-distribution at a $95 \%$ confidence level with the same degrees of freedom, respectively. In other words, there is no evidence of lack of fit for linear model observed and linear regression was significant.

After analytical curve validation (significant regression and no evidence of fit lack fit), LOD and LOQ could be estimated according to International Union of Pure and Applied Chemisty (IUPAC) recommendation. ${ }^{60}$ LOD was estimated as 3 times the standard deviation of the blank measure and LOQ was estimated as being 10 times the standard deviation of the blank measure. Thirty measurements of the blank were use for this purpose yielding values of 2.6 and $7.9 \mathrm{mg} \mathrm{L}^{-1}$ respectively.
In order to estimate the reproducibility of the proposed method 10 successive injections of a $100.0 \mathrm{mg} \mathrm{L}^{-1}$ were carry out and R.S.D. was $1.50 \%$.

\section{Studies of interference in unadulterated samples}

Pharmaceutical formulations may be complex matrixes depending of supplier and the form the medication comes (tablets, ampoules, capsules, gels, lotions, suppositories and ointments) presenting several substances that may cause interferences in the proposed method. An effects evaluation study of common concomitants in the analytical response has to be carry out. Therefore, a assays set was accomplished to establish the tolerance limit of the proposed method. The criteria considering as an insignificant interference the concomitant concentration which produces a variation in the analytical response of a standard solution $\geq \pm 5 \%$ when compared with the same standard solution without the assayed concomitant. Results obtained are shown in Table 4. They are an indicative that the proposed method has a wide tolerance for the assayed concomitants. Consequently, it presents a satisfactory practicality.

Table 4. Summary of the interference effects of pharmaceutical formulations common excipients on the peak height obtained from $100.0 \mathrm{mg}$ $\mathrm{L}^{-1}$ sodium diclofenac solution.

\begin{tabular}{|c|c|c|}
\hline Formulation & Excipient & $\begin{array}{c}\text { Tolerable concentration } \\
\left(\mathbf{m g ~ L}^{-1}\right)\end{array}$ \\
\hline \multirow{4}{*}{$\begin{array}{c}\text { Injectable } \\
\text { solution }\end{array}$} & Mannitol & $3.0 \times 10^{2}$ \\
\cline { 2 - 3 } & Benzyl alcohol & $2.5 \times 10^{3}$ \\
\cline { 2 - 3 } & Propylene glycol & $5.1 \times 10^{3}$ \\
\cline { 2 - 3 } & Sodium metabisulfite & $4.3 \times 10^{2}$ \\
\hline \multirow{4}{*}{ Tablet } & Cellulose & $7.5 \times 10^{4}$ \\
\cline { 2 - 3 } & Starch & $6.0 \times 10^{4}$ \\
\cline { 2 - 3 } & Silicon dioxide & $3.0 \times 10^{6}$ \\
\cline { 2 - 3 } & Magnesium stearate & $2.5 \times 10^{6}$ \\
\cline { 2 - 3 } & Titanium dioxide & $4.0 \times 10^{6}$ \\
\cline { 2 - 3 } & Lactose & $1.5 \times 10^{4}$ \\
\hline
\end{tabular}

Analytical determinations using the proposed method

Table 5 shows that proposed indirect FIA method and reference method yielded similar results determining sodium diclofenac in the two matrixes. In fact, no statistical significant difference was verified between the results by applying the paired $t$-test at the $95 \%$ confidence level. The proposed method presented a precision as good as the reference mode according to values of overall R.S.D. $(\mathrm{n}=5)$ in both matrixes. Such a satisfactory precision must have ascribed to optimization of the operational parameters.

Table 5. Results of sodium diclofenac determinations by proposed and reference methods.

\begin{tabular}{|c|c|c|}
\hline Samples & FIA & Reference Method \\
\hline Injectable solution & $25 \mathrm{mg} \mathrm{mL}^{-1}$ nominal content \\
\hline$(1)$ & $24.8 \pm 0.1$ & $24.7 \pm 0.1$ \\
\hline$(2)$ & $25.0 \pm 0.1$ & $24.9 \pm 0.1$ \\
\hline$(3)$ & $24.7 \pm 0.2$ & $24.8 \pm 0.2$ \\
\hline$(4)$ & $24.5 \pm 0.1$ & $24.6 \pm 0.2$ \\
\hline$(5)$ & $25.0 \pm 0.2$ & $24.8 \pm 0.2$ \\
\hline Overall R.S.D. (\%) & 0.60 & 0.75 \\
\hline Tablet & $50 \mathrm{mg}$ nominal content \\
\hline$(1)$ & $49.8 \pm 0.3$ & $50.0 \pm 0.3$ \\
\hline$(2)$ & $49.6 \pm 0.2$ & $49.4 \pm 0.3$ \\
\hline (3) & $49.8 \pm 0.1$ & $50.0 \pm 0.2$ \\
\hline$(4)$ & $49.8 \pm 0.1$ & $49.6 \pm 0.2$ \\
\hline (5) & $49.4 \pm 0.1$ & $49.8 \pm 0.2$ \\
\hline Overall R.S.D. (\%) & 0.39 & 0.55 \\
\hline
\end{tabular}


Some papers in literature usually compare the analytical performance between different flow analyzers. Frequently these comparisons cannot be consider fair since they are not evaluated on same chemical reactions terms and the real analytical performance is masked by some particular characteristics of each reaction employed. A fair comparison of the analytical performance between different flow analyzers was done in Table 6 . The determination of sodium diclofenac in different matrixes by using the reaction between the analyte and potassium permanganate in acid medium, using the same analytical response was propose. Comparing to other flow analyzers the proposed FIA method provided: wider linear range and satisfactory precision, accuracy and throughput.

Table 6. Analytical characteristics of the proposed FIA system and other flow analysers for determination of sodium diclofenac by reaction with potassium permanganate in acid medium.

\begin{tabular}{|c|c|c|c|c|c|}
\hline Parameter & Proposed & SIA $^{\mathrm{a}} 1^{50}$ & SIA $^{\text {a }} 2^{53}$ & SIA ${ }^{\text {a }}{ }^{61}$ & MCFA $^{\mathrm{b} 62}$ \\
\hline $\operatorname{LOD}\left(\mathrm{mg} \mathrm{L}^{-1}\right)$ & 2.6 & 1.4 & 0.7 & 5.0 & 0.1 \\
\hline Working range $\left(\mathrm{mg} \mathrm{L}^{-1}\right)$ & $25-160.0$ & $10.0-150.0$ & $30.0-135.0$ & $10.0-100.0$ & $20-80$ \\
\hline R.S.D. (\%) & $1.50^{\mathrm{c}}$ & $1.35^{\mathrm{d}}$ & $1.50^{\mathrm{e}}$ & $2.9^{\mathrm{f}}$ & $0.6^{\mathrm{g}}$ \\
\hline Throughput (sample $\mathrm{h}^{-1}$ ) & 80 & Not reported & 120 & 15 & 80 \\
\hline Sample consumption $(\mu \mathrm{L})$ & 50.0 & 50.0 & 50.0 & 120.0 & 20.4 \\
\hline Carrier fluid & Deionized water & Deionized water & $\mathrm{H}_{2} \mathrm{SO}_{4}$ solution & Deionized water & Deionized water \\
\hline Optimization & Multivariate & Multivariate & Univariate & Multivariate & Univariate \\
\hline Sample & $\begin{array}{c}\text { Injectable } \\
\text { solution, tablet }\end{array}$ & $\begin{array}{l}\text { Injectable solution, } \\
\text { tablet and gel }\end{array}$ & Tablet & $\begin{array}{l}\text { Injectable solution, } \\
\text { tablet, gel and urine }\end{array}$ & $\begin{array}{l}\text { Injectable solution, } \\
\text { tablet }\end{array}$ \\
\hline
\end{tabular}

a Sequential Injection Analysis.

${ }^{\mathrm{b}}$ Multicommuted Flow Analysis.

'Estimated from 10 successive injections of a $100.0 \mathrm{mg} \mathrm{L}^{-1}$ sodium diclofenac.

${ }^{\mathrm{d}}$ Estimated from 10 successive injections of a $50.0 \mathrm{mg} \mathrm{L}^{-1}$ sodium diclofenac.

${ }^{e}$ Estimated from successive injections of a $60.0 \mathrm{mg} \mathrm{L}^{-1}$ sodium diclofenac.

${ }^{\mathrm{f}}$ Estimated from 10 successive injection of a $10.0 \mathrm{mg} \mathrm{L}^{-1}$ sodium diclofenac.

${ }^{g}$ Estimated from 10 successive injections of a $100.0 \mathrm{mg} \mathrm{L}^{-1}$ sodium diclofenac.

\section{CONCLUSION}

The viability of a FIA method for indirect determination of sodium diclofenac in injectable solutions and tablets was demonstrated in this work. Thanks to operational conditions optimization, the FIA spectrometric method presented analytical performance as good as other elaborated flow analyzers for analyte determination using the reaction with potassium permanganate in acid medium. The FIA method presented in this work offers a simple and inexpensive way for drug indirect determination aiming at drug quality control in the assembly line of the pharmaceutical industry. However, it cannot be used for adulteration screening analysis due to non-selectivity and non-specificity of redox reactions.

\section{ACKNOWLEDGEMENTS}

The authors thank the Brazilian agencies CNPq and CAPES for scholarship. The authors also thank Dr. David Douglas S. Fernandes for helping in figure and text edition.

\section{REFERENCES}

1. R. L. Souza, M. Tubino, J. Braz. Chem. Soc., 16, 1068, (2011).

2. R. S. Rocha, A. A. G. F. Beati, J. G. Oliveira, M. R. V. Lanza, Quím. Nova, 32, 354, (2009)

3. M. M. Issa, R. M. Nejem, M. Al-Kholy, N. S. El-Abdala, R. S. Helles, A. A. Saleh, J. Serb. Chem. Soc., 73, 569, (2008).

4. E. G. Ciapina, A. O. Santini, P. L. Weinert, M. A. Gotardo, H. R. Pezza, L. Pezza, Ecl. Quím., 30, 29, (2005).

5. The United States Pharmacopoeia - National Formulary, USP-NF XXIII.

6. Farmacopéia Brasileira, Atheneu Editora, São Paulo, 5th edn, 2010.

7. J. Freer, C. Baeza, D. Contreras, C. Soto, S. Corrales, N. Moreno, J. Chil. Chem. Soc., 59, 2632, (2014).

8. European Pharmacopoeia, Concil of Europe, Strasbourg, 3rd edn, 1997.

9. R. T. Sane, R. S. Samant, V. G. Nayak, Drug Dev. Ind. Pharm., 13, 1307, (1987)

10. J. Klimes, J. Sochor, P. Dolezal, J. Körner, Int. J. Pharm., 217, 153, (2001).
11. W. S. Lyra, F. A. C. Sanches, F. A. S. Cunha, P. H. G. D. Diniz, S. G. Lemos, E. C. Silva, M. C. U. Araujo, Anal. Methods, 3, 1975, (2011).

12. M. S. Aurora-Prado, M. Steppe, M. F. M. Tavares, E. R. M. KedorHackman, M. I. R. M. Santoro, J. Assoc. Off. Anal. Chem., 85, 333, (2002).

13. W. R. Jin, J. Zhang, J. Chromatogr. A, 868, 101, (2000).

14. M. E. Abdel-Hamid, L. Novotony, H. Hamza, J. Pharm. Biomed. Anal., 24, 587, (2001).

15. R. Bucci, A. D. Magri, A. L. Magri, J. Therm. Anal. Calorim., 61, 369, (2000).

16. S. A. A. Fattad, S. Z. El-Khateeb, S. A. A. Razeg, M. S. Tawakkol, Spectrosc. Lett., 21, 533, (1988).

17. S. T. Ulu, J. Food Drug Anal., 19, 94, (2011).

18. L. C. Luiz, M. J. V. Bell, R. A. Rocha, T. O. Mendes, V. C. Anjos, R. Bras. Ci. Saúde, 18, 219, (2014)

19. B. K. Chethana, S. Basavanna, Y. A. Naik, Ind. Eng. Chem. Res., 51, 10287, 2012.

20. E. Afshar, F. Jalali, J. Chil. Chem. Soc., 61, 2846, (2016).

21. J. C. Botelho, G. P. Caballero, Talanta, 42, 105, (1995).

22. M. S. Bhatia, S. R. Dhaneshwar, The Eastern Pharmacist, 38, 133, (1995)

23. Y. K. Agrawal, K. Shivramchadra, J. Pharm. Biomed. Anal., 9, 97, (1991).

24. S. Agatonović-Kuštrin, L. Živanović, D. Radulović, M. Vasiljević, Analyst, 116, 753, (1991).

25. C. S. P. Sastry, A. S. R. P. Tipirneni, M. V. Suryanaryana, Analyst, 114, 513, (1989).

26. B. V. Kamath, K. Shivram, Anal. Lett., 26, 903, (1993).

27. S. Agatonović-Kuštrin, L. Živanović, M. Zečević, D. Radulović, J. Pharm. Biomed. Anal., 16, 146, (1997).

28. R. Bucci, A. D. Magri, A. L. Magri, Fres. J. Anal. Chem., 362, 577, (1998).

29. M. L. F. Cordova, P. O. Barrales, A. M. Diaz, Anal. Chim. Acta, 369, 262, (1998).

30. B. V. Kamath, K. Shivram, G. P. Oza, S. Vangani, Anal. Lett. 26, 665, (1993).

31. Y. K. Agrawal, V. P. Upadyay, S. K. Menon, Indian J. Pharm. Sci., 50, $58,(1988)$.

32. Z. A. E. Sherif, M. I. Walash, M. F. E. Tarras, A. O. Osman, Anal. Lett., 30, 1881, (1997)

33. I. Kramancheva, I. Dobrev, L. Brakalov, Anal. Lett., 30, 2235, (1997). 
34. Y. C. de Micalizzi, N. B. Pappano, N. B. Debattista, Talanta, 47, 525, (1998).

35. A. M. El-Didamony, A. S. Amin, Anal. Lett., 37, 1151, (2004)

36. R. L. Souza, M. Tubino, J. Braz. Chem. Soc., 16, 1068, (2005).

37. A. A. Gouda, M. I. Kotb El-Sayed, A. S. Amin, R. El Sheikh, Arab. J. Chem., 6, 145, (2013).

38. Z. Song, N. Zhang, Talanta, 60, 161, (2003).

39. P. L. Weinert, L. Pezza, H. R. Pezza, J. Braz. Chem. Soc., 18, 846, (2007).

40. P. T. Anastas, Crit. Rev. Anal. Chem., 29, 167, (2010).

41. F. R. P. Rocha, B. F. Reis, E. A. G. Zagatto, J. L. F. C. Lima, J. L. M. Santos, Anal. Chim. Acta, 468, 119, (2002).

42. A. Parikh, K. Patel, C. Patel, P. B. N., J. Chem. Pharm. Res., 2, 118, (2010)

43. J. Ruzicka, E. H. Jansen, Anal. Chim. Acta, 78, 145, (1975).

44. D. A. Skoog, F. J. Holler, T. A. Nieman, Principles of Instrumental Analysis, $4^{\text {th }}$ Edition, Saunders College Publishing, New York, 1992.

45. M. S. García, M. I. Albero, C. Sánchez-Pedreño, J. Molina, J. Pharm. Biomed. Anal., 17, 267, (1998).

46. S. García, C. Sánchez-Pedreño, I. Albero, C. García, Mikrochim. Acta, 136, 67, (2001)

47. B. V. Kamath, K. Shivram, A. C, Shah, J. Pharm. Biomed. Anal., 12, 343 (1994).

48. S. S. Simões, E. P. Medeiros, E. N. Gaião, W. S. Lyra, P. N. T. Moreira, M. C. U. Araújo, E. C. Silva, V. B. Nascimento, J. Braz. Chem. Soc., 17, 609, (2006).
49. F. F. Gambarra, R. S. Lima, W. S. Lyra, G. Marino, M. C. U. Araujo, E. P. Medeiros, V. B. Nascimento, Anal. Lett., 40, 3070, (2007).

50. A. M. Idris, Chem. Cent. J., 5, 9, (2011).

51. M. A. Morsy, M. M. Khaled, Spectrochim. Acta A, 58, 1271, (2002).

52. J. Neugebauer, E. J. Baerends, M. Nooijen, J. Phys. Chem. A, 109, 1168, (2005).

53. S. M. Sultan, H. D. Mohamed, A. Jaber, N. A. Alarfaj, J. Flow Injection Anal., 27, 49, (2010).

54. B. N. Figgs, Introduction to ligand fields, Interscience Publishers, 1966.

55. E. Morgan, Chemometrics: experimental design, John Wiley \& Sons, London, 1991.

56. D. C. Montgomery, Design and analysis of experiments, John Wiley \& Sons, New York, 1997.

57. J. N. Miller, J. C. Miller, Statistics and chemometrics for analytica chemistry, Pearson Prentice Hall, Harlow, 2004.

58. R. E. Bruns, I. Scarmínio, B. Barros Neto, Statistical design: chemometrics, Elsevier, Amsterdam, 2006.

59. N. R. Draper, H. Smith, Applied Regression Analysis, $3^{\text {rd }}$ Edition, Wiley, New York, 1998.

60. IUPAC, Pure Appl. Chem., 45, 99, (1976).

61. J. A. Rodriguez, G. Islas, M. E. Paez-Hernadez, E. Barrado, J. Flow Injection Anal., 25, 39, (2008).

62. P. R. Gomes, H. S. Lima, A. J. D. Lima, R. N. Fernandes, W. S. Lyra, F. A. S. Cunha, E. F. Silva, M. L. B. Ferreira, W. S. Lima, Rev. Virtual Quím., 9, 563, (2017). 